\title{
A Study of Toddlers' Humor Linguistic Mind
}

\author{
Dian Eka Chandra Wardhana*, Gita Mutiara Hati \\ Faculty of Teacher Training and Education Universitas Bengkulu
}

\section{A RT I C LE INFO}

Keyword:

Humor

linguistic mind

ambiguity

\begin{abstract}
A B S T R A C T
Humor for a child can improve his intelligence and smooth his feeling and as a result, he has a strong mental endurance which affects physical stamina. Humor is considered as a language play in several aspects of language structure and function. Therefore, this study explains the linguistic view which explicitly and implicitly used by the speaker when telling humor. This is a qualitative study with ethnography of communication and pragmatic approach. The data are in the form of toddlers' speech when they are communicating using humor which is represented while they are playing with their families and playmates. The data was then documented in the form of descriptive and reflective recording and field notes. The findings of this study show that humor is represented through language play such as pragmatics, syntax, morphology, phonology, and semantics in language mind with implicit meaning. Therefore theories of ambiguity play a role in linguistic mind. However, this study only focuses on the discussion of humor in toddlers' linguistic mind which is represented in their speech act.
\end{abstract}

(c) 2017 ISLLAC Journal. All rights reserved

\section{INTRODUCTION}

Being competent language users for toddler means that they are able to talk and communicate interactively with other peers. When communicating with peers, toddlers tend to use language play. It is a form of language which has its own rules, and it is grammatically different from adults' language. This language play used by children is considered by an adult as humor and it may be used as media for children in learning a language.

Funny children's language play is a fun game (Buzan, 2005:12) so it will be impressive for the children. When children feel happy, it is most likely that the acquisition of the language will retain much longer (Darjowijoyo, 2008: 278). A similar thought is also stated by Debra (2014:14) who says that humor among children is a game in which children combine parts of language with their logic. As a result, adults realize that this game is beneficial in improving children's language competence. However, a semantic expert Pierre Guiraud $(1976,1981)$ in Debra $(2012: 15)$ has a different opinion. He says that the language play demonstrated by a child is often the activity of a language 'defunctionalization'. It means that this language play is simply a game, not for particular purposes in language activities. Therefore, in a context where the language play is used as a medium of communication, a child is actually speaking in a sound stream and peers have to understand the language in order to be able to unravel what is heard into the components of phrases, words, and morphemes. This component randomly deciphers the sounds and associate them into specific phrases with unclear meaning. That is why it can be said that language play is not-functional language activities.

The following example is taken from Debra (2012:13), who says that a two-year-old child's language development can be seen from his/her language representation. A child says 'I am sticky' which his actual meaning was he has found wood chips patched on his fingers. This child obviously has generalized a certain rule because in the same week he said: "I roof the ball" which means he just throw a ball to the roof. Although it is uncommon, the listener can still understand what he actually means. Another example by Debra (2012:14) is "I collecting papers in a file so I file the papers", "I put fruits in a bottle so I bottle the fruits." These sentences follow the rules that a sentence consists of a verb phrase and sometimes it is added with noun phrase and prepositional phrase. It is supported by

\footnotetext{
${ }^{*}$ Corresponding author.

E-mail addresses: dian_eka09@yahoo.com (Dian Eka Chandra Wardhana)
} 
Bower Man (1986) in Debra (2012:15) who gives example 'Giggle me' which means the child is asking someone to make her giggles. It seems that it has the same rule with 'Tickle me' or 'Bring me'. These examples give transparent side in the process of children' s language acquisition.

Those phenomena explain the basic characteristic of humor which could represent a child's mind. It is because humor consists of independent units which describe language and mind characteristics. Another example is shown when a child calls his father 'Mas Bapak' after he was separated from his father for some time during his toddler age. This is due to the fact that his father was not around in his baby life and he knew that older and bigger man adult is called 'Mas' in Javanesse culture. It is crystallized in the child' s mind since he is exposed to this all the time (Darjowijoyo, 2005:278). Therefore he has failed to realize that this big older man who is his mother' s husband should be called differently from other big adult men in his surroundings.

Language play which is represented by this child is the kind of children's creative use of language which is actually interactive. Sometimes this language play is dysfunctional since his language play is represented as a ball game (Debra, 2012:161-170). It means that when a child is playing with the language, the sounds of the language is arranged, rearranged, repeated, played back, sung, shouted, whispered, and extended just like the language is played for the sake of its own. A child's language competency is at least a set of linguistic elements that are limited by the child' s own mind. Therefore, humor is seen as a linguistic ambiguity or basic issues from the circle of ambiguity (Debra, 2012:158). Recognizing a humor needs a hidden knowledge from a language competence which as a result leads to grammatical knowledge because humor is a product of language play which can be used to see what happens (or possibly) happens in the child' s world and particularly what happens in the child' s mind.

Playing is fun. Every person has a set of play, either in form of language elements or rules combined with those language elements though some of us are not aware of it. Likewise, toddlers in a tacit way take adults as their role models in using a language (Darjowijoyo, 2008:273). Adults should be aware of this role because the good experience will bring better development for children. It is supported by several previous studies (Oberlander, $\mathrm{R}$ June $2008, \mathrm{Al}$ Faruq, Assadulloh, 2010, dan Raja, Patuan, 2004) so that a study about humor and linguistic mind is found to be interesting to conduct. This study explains about toddlers' humor and the content of the linguistic knowledge in their minds, either explicitly or implicitly.

This is a qualitative study with ethnography of communication and pragmatic approach. The data are in the form of toddlers' speech when they are communicating using humor which is represented while they are playing with their families and playmates. The data was then documented in the form of descriptive and reflective recording and field notes. The data was analyzed using Miles dan Huberman's (1984) flowchart and was started from the very beginning of data collection stage. The validity of the analysis result was ensured by the use of correct data collection technique as well as through intensive discussion with other colleague researchers.

The clarity of toddlers' humor is seen from the content of linguistic knowledge in their minds, either explicitly or implicitly. It is represented through the use of the language functionally. In addition, the language is also used in a defunctionalized way. It is due to the fact that toddlers' language competency and creativity is only for babbling with no functional clarity of meaning. The following is the more detailed findings of this study.

\section{HUMOR AND THE LINGUISTIC MIND OF TODDLERS IN THE USE OF LANGUAGE}

Humor and the linguistic mind of toddlers are represented through the use of language functionally as a mean of communication. Toddlers are funny. Often they are being funny when they accidentally show their creative use of language because their language competency is not fully developed. This creativity is built based on their tacit language experiences.

Humor in toddlers' linguistic mind uses elements in a language. It is important to notice so that rules, characteristics, and the purpose of humor represent the toddlers' mind through the language, either explicitly or implicitly. The following are the detailed findings of the data analysis.

(1) Humor which represents linguistic mind resulted from toddlers' creativity

Toddlers' competence and creativity in using a language are very remarkable and sometimes it is found to be funny. It is due to the fact that a native speaker can produce a language by making a grammatical judgment which is related to their native vocabularies. It is not important to them whether or not they have heard these combinations of vocabularies. It is something wondrous when it comes to the thinking that learning is actually a simple storage process and if it is done in a fun way it will be crystallized in the learner' s mind. Therefore, the result will be perfectly exposed in the future (Chomsky, in Eerdmans, L Susan, 2002:151). However, it is very difficult to prove how the process takes place because it is something abstract happening in mind (Darjowijoyo, 2008:272). This linguistic creativity leads to the question whether or not Chomsky has differentiated relevant examples of linguistic competence and creativity. It seems that the answer is no. It is based on the arguments about children's ability in making a grammatical judgment from sentences which exposed from LAD and the judgment is in fact grammatically and logically valid. This judgment is important and fundamental; even though the speaker of the language is perhaps illiterate or still young. This thing is related to the possibility that limited grammatical competency Chomsky wishes to explain is actually a new breakthrough and can only develop in several cultures. New logic and valid theoretical constructions are possible to be exposed.

Example (1) a child calls his mother 'aunty mommy' when he met her again after several years being parted. He failed to remember that his mother is actually called 'mommy'. What he knew was that middle-aged women in his surroundings were called 'aunty' . This knowledge was acquired in a tacit way from his surroundings. 
That is why he called his mother 'aunty mommy' after being separated for several years. This phenomenon is supported by the example (2) in which a child with the similar situation called his father 'uncle-father' dan 'mas father'. In addition, there is, in fact, an example (3) in which a child called his mother 'granny mommy' since he met again with his mother after several years apart and his mother looked much older like a granny.

Those addresses in example (1), (2) dan (3) feels funny since, in the adult grammar, the data is collected by exploiting the ambiguity of the word 'aunty' and 'mommy'. These two words have different meaning and use. The word 'aunty' is usually used by a child to address a middle-aged woman who is not his mother. In this case, the normative language rule is mixed up. As known to many people, a name is used as a tool to show a unique description of each individual. Calling a person with two different addresses at once will make confusion. This happens due to solidarity reason by calling a person with double addresses. Addressing someone is actually related to the strength of illocution because different address shows the different relation between one another. For example, the relation between the teacher and students, the head and the employees, hierarchical relationship leads to only one address to call someone.

Example (4) 'Aku kesemutan' (bitten by ants) is a representation of funny toddler language because of it ambiguous. In the Indonesian language, the expression 'kesemutan' means feeling tingling on a particular part of the body, while what actually happens is that the child is bitten by ants. That is why 'Aku kesemutan' sounds funny to adult. In the toddler's mind, the language used is formulated based on personal freedom, because most of us do not like to be taught when we speak. It results in the use of descriptive language learning strategy instead of prescriptive. Most people do not find any rules to be followed, except for written form. It perhaps has something to do with mutual agreement. The prescriptive approach to language is somewhat confusing to teachers because it is considered difficult when it comes to the use of a language. The explanation is supported by the fact that most of the people do not like to be taught how to speak. Example (5) shows that a child said that he had a 'miskram'. It is very confusing since 'miskram' is an expression of miscarriage, while there is no way a child could be having a miscarriage. Whereas what is meant by the child as he had a cramp in his hand. In Indonesian language, cramp is called 'kram', but this child slipped off his tongue and said it as 'miskram' .

In above case, the ambiguity theory is applied in order to interpret what the speaker is actually saying. This is a 'no meaning' theory in which at first the listeners do not give any interpretation of the sentence, but to wait until the context gives away the correct interpretation. However, different explanation applies in the English language. Debra (2012:13) says that a two-year-old toddler's language competence development can be seen from his language representation. A child says 'I am sticky' which his actual meaning was he has found wood chips patched on his fingers. This child obviously has generalized a certain rule because in the same week he said: "I roof the ball" which means he just throw a ball to the roof. Although it is uncommon, the listener can still understand what he actually means. The explanation of these examples is supported by other data in this study. Example (6) 'I am wormy' , (7)' I box the toys' , (8) I garage my bike, (9) I garbage the oranges, (10) I mountain the sands on the beach, dan (11) I glass the water in the kitchen.

Furthermore, example (12) was represented with different speech, 'I drink milk tea' which the actual meaning is this child only drinks tea, not milk. This data shows that children with a pure linguistic mind can produce a language well. Starting from the very early age, a child can communicate fluently and produce well-formed speeches based on the linguistic standard. This is possible because children learn more on the language instead of the language rules. Grammar competence is considered unimportant because it is still doubtful whether or not that adults have that competence. Hence, communicative competence is regarded very important (Campbell dan Wales, 1970 in Eerdmans L Susan e.al., 2002). In other words, children's linguistic mind focus is directed to the mastery of language, not in a context of orderly sentence structure (Lyons, 1977 in Raja 2005). As a result, learning activities are not only reflections of children's interest but also related to linguistic competence as a reasonable concept for children.

This phenomenon means that communicative competence is not equal to the language performance or creativity. Native speakers' creativity and competency inappropriately producing and interpreting speech which has not been heard before are not doubted because with that creativity children will likely to be resilient and survive with their native language values. Therefore, the ability to create new 'surprising' speeches becomes the domination in children mind. This statement is supported by the example (13) "I drink glass-milk' which means milk brewed in a glass, not in a bottle, an example (14) 'I drink father' s syrup' which in this case syrup means coffee.

This finding is in a line with Bloomfield's (1926) opinion in Raja (2005) about natural language. Bloomfield says that the totality of a speech which can be produced in a language community emphasizes on the competence, not on the linguistic accuracy. It is not grammatical form explanation, but it is based on the control of the linguistic features such as deictic reference, greetings, and speech act. Grammatical appropriateness criteria only apply to the adult grammar competence.

Other findings are different from adult logic. Example (15) shows a child addresses his aunty's baby as 'mas kecil' which means 'little big brother' because in his culture he must address this baby as big brother. Another example, example (16) 'kacang pendek' which means long beans cut short. Humor from data (16) is strengthened by the following example (17) 'baby fish' which refers to anchovy which is small in the size. Example (15), (16), and (17) show funny children's creative use of language. The data are considered creatively funny because the interlocutors take on what they know about language form and how the language works in children' $s$ mind. That is why the speeches seem funny. Humor on the data shows inherent ambiguity in the linguistic structure.

The following example is a kind of humor which emphasize on children's language function. Example (18) shows 'Hafid train' in which the actual meaning is this child wants to take the train when his father is planning to 66 | ISLLAC : Journal of Intensive Studies on Language, Literature, Art, and Culture 
have a holiday in Central Java. Another example is an example (19) "Mika poweranjes" which means Mika wants to be a power ranger when she is playing with her playmates. Those data are the examples of humor with the repetition of speech function in which there is a close relationship between the language function and children's logical function. These data also support the Chomsky's theory and they challenge the creativity or argument to separate competence as a learning object from the performance. Creativity is regarded as a view which is modified from particular details of a competence. Meanwhile, performance is understood as a modified form of the competency. Therefore, it is possible to argue against Chomsky's theory about the competency being a generative system and explicitly specify the thread line which makes up a sentence. This kind of effort is made to obtain a discrete statement, although not everyone considers this to be reasonable (cf. Hockett, 1968; Lakoff, 1971 in Raja 2005). It makes more difficult to decide whether or not communicative function is generative, or even raise a probability statement about the correct use of a sentence.

\section{HUMOR REPRESENTATION AND DYSFUNCTIONAL TODDLERS' LINGUISTIC MIND}

This humor representation and dysfunctional toddlers' linguistic mind is represented because toddlers are using it for relaxation and to reduce stress. Based on the data analysis, even toddlers laugh when they listen to odd words or linguistically not standard. Various creative games are created by a neurologist to stimulate and motivate children's healthy physic and psychology. Example (21) shows a child shouted 'obu...obu...' imitating scooby-doo character when she felt bored spoonfed by her mother. These bablies are frequently repeated because her mother spoonfed her quietly for about two hours and even more. This unmeaningful sound production was shown monotonously so it does not seem interactive and funny to the listener. Based on the analysis, the data is considered as a dysfunctional language and it can be harmful to the toddlers since their language may not be developed either in terms of vocabulary or grammar. Hence, it is worrying. Even though this child is capable of saying (22) 'hello' and (23) 'bye' in a significant context, language competence should be led to more functional competence.

Supporting phenomenon is shown in the example (24). The context was a child feeling stressed because he was left with a caregiver while his mother was working. Feeling uncomfortable, he suddenly screamed for his mother (24) 'mommy...mommy...mommy...' . Meanwhile, his caregiver said that the child was in a comfortable situation. A semantic expert Pierre Guiraud (1976, 1981 in Debra, 2012) calls this situation as a defunctionalization of a language. It means that the language activity is only for language play, not for the sake of the language itself. This finding can be seen from the way the speaker plays with an object. This way can tell us the basic linguistic characteristics of the speaker when he wants to release the pressure on his mind. Funny utterances are independent units which can give us information about the language characteristics and the mind which process the language. Very often humor is told in an interaction. However, when a language play is not limited to communicative or personal function, then Aquinas describes it as a funny language use (Aquinas, Summa Theologia, Question in Aora Debra, 2012:168). The use of defunctionalized language is a language function for the sake of the language, not for the sake of the speaker. Even though we can entertain ourselves by playing, it will be much fun to play with other people. It means that playing with a language is more likely to be more fun if it is done in an interactive and reflective way.

To sum up, humor processing in children's linguistic mind needs the function of both right and left hemisphere of the brain (Buzan, 2005:10) because in fact both parts of the brain work collaboratively in interpreting the language play(Gardner et al., 1983 in Aaron, Debra 2012:14). Same thing applies when a person is listening to mutarajul Quran. It is found that both brain hemispheres are collaborating in order to be able to 'enjoy' listening to the verses (Hendraningrum, 2011).

\section{IMPLICATION IN LEARNING}

In language learning nowadays, language creativity is considered as important as literacy and there is a need to treat both with similar ways (Ken Robinson, in Simister, 2009:87). It is because language creativity in a functional way can build children's character as a social creature since children's language habit is used in fun interactive activities (Ayah Edi, 2012:157-174) so that children' s character can be built through the use of humor in language. The implication in language learning is the use of active creative learning method.

Humor is a product of language play to see the possibility of what may happen. Playing is fun and every person has a set of games which are useful for serious activities. It is supported by Bateson (1976), an anthropologist and polymath, who discusses games and ideas of language games. He shows that language games can be characterized based on the additional metacommunicative act (Bateson, 1976: 121). Therefore, the concept shows that both hemispheres of the brain are involved in the semantic activity, as long as the learning about jokes is applied (Kandhadai, Federmeier, 2008) and metaphorical language processing does not activate the brain in the same way the jokes do. The right hemisphere of the brain shows its performance though a bit slower. As a result, both hemispheres of the brain will process metaphorical language similarly (Coulsun and Van Petten, 2007 in Debra 2012)

Linguistic processing in linguistic jokes should have implication to the left hemisphere of the brain. It is seen on the language play (Coulson and Severens, 2007 in Debra 2012) which has demonstrated that although left hemisphere of the brain is involved in interpreting ambiguity meaning of a word, the right hemisphere of the brain is only involved with the most closely related meaning. However, both meanings are active in both hemispheres of the brain.

\section{CONCLUSION}

Humor representation of toddlers' functional linguistic mind is based on the consideration that the linguistic mind has worked in a tacit way in processing general sociopragmatic knowledge. Several linguistic creations made by toddlers use similar features found in linguistic jokes. It reveals the conscious knowledge about the language rules 67 | ISLLAC : Journal of Intensive Studies on Language, Literature, Art, and Culture 
applied during a play time. It is very common that linguistic creations are used as a parameter in the development of first language acquisition. Meanwhile, humor representation and defunctionalized linguistic mind is a creativity made for a play which is oriented for the sake of the language, not for the speaker. It is not recommended for language acquisition because language activities should better be done in an interactive and reflective way.

\section{REFERENCES}

Asadulloh, Al-Faruq. (2010). Mendidik Balita Mengenal Agama. Jakarta: Kiswah

Buzan, T. (2005). Mind Map for Kids, Max your Memory and Concentration.China : South Cina Printing Co.Ltd

Clark, E. V. (2003). First Language Acquistation. Cambridge : University Press

Crystal, D. (1988). Joke and Their Relation to Society. Berlin and NewYork : Mouton de Gruyter

Darjowijoyo, S. (2008). Psykolinguistik, Pengantar Memahami Bahasa Manusia. Jakarta :Yayasan Obor Indonesia

Debra, A. (2012). Jokes and The Linguistic Mind. New York : Routledge Eerdmans, L S., ET. All. (2002). Language and Interaction, discussions with John J Gumperz. Philapeldia, USA: john Benyamin Publisher

Edi, A. (2012). Ayah Edi Menjawab. Jakarta:PT Mizan Publika

Orberlander, R. J. (2008). Slow and Steady Get Me Ready, Buku PedomanPengembangan Anak Usia Dini. Jakarta: Gramedia

Hendraningrum, A. P. (2011). Analisis Pengaruh Muratal Al-Qur'an Terhadap Data rekam EEG Menggunakan Transformasi TF dan STEF. Yogjakarta : Skripsi UGM Tidak diterbitkan

Hoff, E. (2005). Language Development Fourt Edition.USA: Wadswort

Kushartanti. (2006). Bahasa Indonesia Baku dan Tak Baku pada Percakapan AnakJakarta. Jakarta : Linguistik Indonesia, 24 no.1.

Setyorini, A. (2013). Anak-anak Cemerlang. Jakarta : PT.Serambi Ilmu Semesta 